\title{
DISCURSO E IDENTIDADE DOCENTE: UM ESTUDO COMPARATIVO DAS CAPAS DA REVISTA NOVA ESCOLA
}

\section{SPEECH AND TEACHING IDENTITY: A COMPARATIVE STUDY OF THE COVERS NOVA ESCOLA MAGAZINE}

\author{
Silvanya Suellem de Lima Romeu*
}

\begin{abstract}
Resumo: A revista Nova Escola é uma publicação brasileira com periodicidade mensal e de ampla circulação nos meios educacionais. Desde o seu surgimento em 1986, o impresso se posiciona como objeto necessário para informar, atualizar e auxiliar o professor a desenvolver boas práticas educativas. Identificada como "a revista de quem educa", demonstra ser terreno fecundo para as investigações no campo da Educação. Questionamos como o professor é identificado no discurso das capas de Nova escola. Para compreender o objeto - sujeito professor - do qual trata este estudo e responder à problematização já estabelecida, objetivamos comparar duas capas da revista (edições 116 e 216), selecionadas para representar uma década (1998-2008), e analisar a identidade docente no impresso. Os resultados da análise apontam para a construção de duas identidades opostas do professor: preparado e desqualificado. Tais resultados foram alcançados a partir do método arquegenealógico de Foucault que nos permitiu observar as estratégias discursivas da revista como mecanismo de identificação do sujeito professor.
\end{abstract}

Palavras-chave: Discurso. Identidade. Professor. Revista Nova Escola.

\begin{abstract}
Nova Escola is a monthly Brazilian magazine with wide circulation in educational environment. Since it has been appeared in 1986, this printed magazine is positioned as a useful object to form, update and help teachers to develop good educational practices. It is identified as "the magazine of those who educate" and demonstrates to be a fruitful space to investigations in the field of Education. We question how the teacher is identified in the speech of Nova Escola magazine covers. To understand the object - subject teacher - of whom this present study treats and answer the problematization was established, we want to compare two covers of the magazine (116 and 216 editions), which were selected to represent a decade (1998-2008), and analyse the teacher identity in the magazine. The results of the analysis point to construction of two opposing teacher identities: prepared and disqualified. These results were achieved from the Focault's Archaeological Method which allowed us to observe the discursive strategies of the magazine as a mechanism of identifying the subject teacher.
\end{abstract}

Keywords: Speech. Identity. Teacher. Nova Escola magazine.

\section{Introdução}

Cada vez mais, a relação dos professores com o conhecimento tem-se tornado tema amplamente discutido em diferentes instâncias sociais como na academia, nas escolas, nos documentos oficiais e inclusive na mídia, considerando-se diferentes perspectivas, as quais dão conta da qualidade da formação docente, do acesso às informações, do conhecimento que o profissional provavelmente desenvolve, como e o quê deve ou não ensinar e para quem ensinar.

Essas discussões acabam por constituir um cenário para a educação, o qual tem o professor como ator social responsável pelo processo de ensino e de aprendizagem. As discussões igualmente contribuem, por intervenção da mídia no processo de forte repercussão, tanto na formação de professores como na formação de opiniões sobre o

\footnotetext{
* Mestre em Linguagem e Ensino pela Universidade Federal de Campina Grande. Doutoranda em Educação pela Universidade Lusófona de Humanidades e Tecnologias na área das Ciências da Educação. silvanya.suellem@hotmail.com
} 
que significa ser professor. Assim, as formas de atuação dos professores e os modos de dizer sobre eles nas diferentes instâncias, delineiam e constituem as múltiplas imagens da função social docente, e imprimem diferentes identidades para esse profissional da educação.

Uma entre tantas questões abordadas nessas discussões é a de como o professor desempenha essa função e quais instrumentos auxiliam a sua prática. Nesse sentido, é válido destacar que a atualização constante do conhecimento deve sempre manter relação com o efetivo exercício da prática docente. Motivado por esta questão, o mercado editorial brasileiro disponibiliza a um público específico diferentes periódicos sobre educação como recurso que poderá subsidiar a ação do educador, promovendo a este um conhecimento pedagógico atualizado.

Nesse sentido, a revista Nova Escola da editora Abril, é uma publicação jornalística de linha educativa, já consolidada no mercado editorial brasileiro desde 1986. É reconhecida pelos professores da Educação Básica no Brasil como a marca de maior credibilidade nesse setor. Seu conteúdo é exclusivo para educadores, prioritariamente, da educação básica e tem por finalidade informar e atualizar seus leitores sobre práticas de ensino bem sucedidas, realizadas por docentes de diferentes estados brasileiros. Esta produção cultural ainda apresenta reportagens que abordam temas diversos - fora da sala de aula - no campo educacional. Desse modo, observamos que a revista ultrapassa seu principal objetivo de informar e acaba por influenciar os professores leitores a um modo legítimo de ser professor, pois a medida que seus textos informam uma série de conhecimentos sobre boas práticas pedagógicas, também imprimem e fazem circular imagens autênticas desse profissional da educação para seus interlocutores, os professores leitores.

A partir dessas observações, começamos a levantar vários questionamentos sobre a imagem do professor na revista Nova Escola. Como o professor é identificado no discurso das capas da revista Nova Escola? De que maneira a revista apresenta a seus leitores uma forma legítima de ser professor? Entendemos que o impresso enquanto produto da cultura midiática tanto tem o poder de informar e atualizar quanto de induzir os modos de ser e, por consequência, produz identidades para o sujeito professor.

Por isso, uma vez que já percebemos o que ela faz, buscaremos agora compreender não o quê, mas o como ela faz. Interessa-nos observar os mecanismos discursivos que possibilitam os efeitos de sentido produzidos pelos enunciados constitutivos das capas de Nova escola. A inquietação que nos move neste estudo procura explicitar as identidades construídas para o professor através do jogo estratégico do poder que atravessa as capas do impresso e conduz o leitor a identificar um modo legítimo de ser professor.

Assim, este trabalho se insere no âmbito das discussões acerca dos estudos tanto na área da educação como da linguagem, proporcionadas por especialistas que têm apontado como objeto de estudo os discursos em circulação na revista Nova Escola com o objetivo de compreender os processos que constituem a identidade docente nesse veículo, o qual tem o professor como público-alvo. É válido esclarecer que concebemos a produção de identidade como um evento de discurso, que está sujeito ao desafio da descrição e interpretação. Nesse sentido, de acordo com Pêcheux (1990, p. 17), o pioneiro da Análise de Discurso Francesa, o acontecimento discursivo se dá "no ponto de encontro de uma atualidade e uma memória", onde são formulados os efeitos de sentidos de um enunciado. Para Foucault (2009, p 22), "os discursos, indefinidamente, para além de sua formulação, são ditos, permanecem ditos e estão ainda por dizer". De acordo com o que afirmam esses teóricos, há um entrecruzamento na formulação 
imediata do sujeito do discurso com a existência anterior de um enunciado, o qual se atualiza na prática discursiva. É justamente esse ponto de encontro, do qual fala Pêcheux e compreende Foucault, que garante o 'acontecimento discursivo' que autoriza a interpretação dos sentidos possíveis no texto.

Neste artigo, apresentamos um estudo analítico comparativo de duas capas das edições da revista Nova Escola (outubro de 1998 e outubro de 2008). As capas selecionadas constituem as duas publicações referentes ao mês no qual é celebrado o dia do professor e considera um recorte cronológico de uma década, sem importar o conteúdo da capa. O presente estudo está vinculado ao projeto de pesquisa ainda em andamento, o qual inclui uma análise da revista Nova Escola, a partir dos discursos constitutivos de seus textos, os quais dizem respeito à prática docente e aos modos como se apresenta e é constituída a subjetivação e a identidade docente.

Diante do objeto de estudo apresentado, optamos pelo suporte teórico, metodológico e analítico da Análise de Discurso de linha francesa, sobretudo, as reflexões de Foucault $(2014 ; 2009 ; 2010 ; 1979)$. As análises buscam dar visibilidade aos processos discursivos que determinam efeitos de verdade estabelecidos entre técnicas de saber e estratégias de poder que se articulam no conjunto das significações e perpassam as construções identitárias. Trata-se de compreender as regras de controle daquilo que pode ser dito por alguém em determinada circunstância, instaurando assim uma ordem. A ordem do discurso empreendida por Foucault, estabelece o regime do que deve ser considerado verdadeiro num domínio determinado.

Nesse contexto, buscamos observar e discutir, dentro dos limites e possibilidades deste trabalho, que o discurso qualificado como verdadeiro construído no impresso de linha educativa ocorre a partir da estratégia de imposição sobre outros discursos rejeitando-os ao terreno do falso, instaurando por sua vez a ordem do discurso verdadeiro sobre ser professor na realidade do Brasil. Desse modo, a regularidade discursiva constitui o critério normativo tanto para impor significações quanto para identificar os sujeitos de ensino. Os indícios de autoria também são considerados para fins de análise, pois contribuem para a reflexão acerca de onde enuncia a revista Nova Escola, e de quais estratégias faz uso para dar voz ao outro ou manter distância daquilo que enuncia.

\section{A revista Nova Escola: uma publicação na linha do jornalismo educativo destinada à valorização docente e ao incentivo a melhoria da educação pública brasileira}

Dentre as revistas cuja temática é educação, Nova Escola é considerada a revista precursora na área de Educação no Brasil, estabelecendo-se como fonte de referência para educadores, dentre eles, os professores do ensino fundamental. Nova Escola é um periódico educacional mensal com publicação de 10 exemplares anuais, pois nos meses de jun/jul e dez/jan, dedicado às férias, ocorre uma única edição para cada intervalo, a qual coincide com o período de descanso dos escolares.

Lançada no Brasil, posteriormente ao fim da Ditadura Militar, em março de 1986, a revista é divulgada como uma publicação da Fundação Victor Civita (FVC), a qual foi criada em 1985, sendo parte integrante do grupo empresarial iniciado com a 
Editora Abril ${ }^{1}$, com diversificada e extensa atuação no mercado brasileiro (Revah, 2013). Após 30 anos de publicação da revista Nova Escola, a FVC anuncia a transferência da marca Nova Escola para a Fundação Lemann ${ }^{2}$ com o argumento de dar novo vigor à revista e contribuir para o seu crescimento.

Há 32 anos compartilhando experiências de práticas educativas bem sucedidas, Nova Escola tem destino certo: os educadores, embora seu principal alvo seja o professor. Desde o princípio de criação, seu objetivo era contribuir para melhorar a qualidade da educação pública no Brasil e para isso acreditava na participação do professor. Nesse sentido, o projeto da FVC, que se denomina entidade sem fins lucrativos, recebeu apoio financeiro de algumas empresas privadas e assinou contrato com o Ministério da Educação (MEC), consolidando uma parceria que rendeu distribuição mensal e gratuita dos exemplares da revista para cada uma das 220.000 escolas públicas de $1^{\circ}$ Grau existentes no Brasil nesse período (NOVA ESCOLA, $\mathrm{n}^{\circ} 1$, 1986, p.5). Tal parceria com o MEC, de acordo com Costa e Silveira (1998, p. 347), sustentou um contrato de assinaturas de 300.000 exemplares, o qual correspondia ao financiamento de $70 \%$ das publicações de Nova Escola.

$\mathrm{Na}$ edição de lançamento da revista, Victor Civita, editor do impresso, nega o seu caráter pedagógico, embora admita a participação de profissionais da educação na equipe que a produz e evoca a figura feminina docente quando se dirige aos seus destinatários com o seguinte discurso:

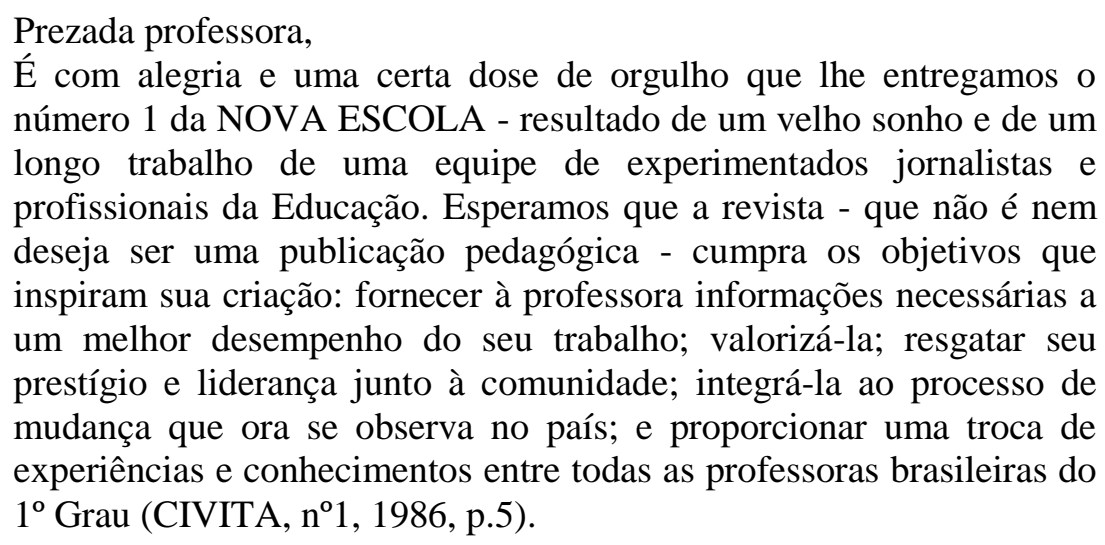

O impresso idealizado por Victor Civita segue a linha do jornalismo educativo sob o propósito de informar e inspirar o corpo docente brasileiro, sobretudo as professoras, a desenvolver boas práticas educativas, além de contribuir para o resgate da valorização do profissional de ensino e da melhoria da Educação brasileira, ambos necessários ao processo de mudança estabelecido no país no momento de criação da revista.

\footnotetext{
${ }^{1}$ A Editora Abril foi oficialmente inaugurada por Victor Civita em 1950 e logo tornou-se a maior editora de revistas comerciais do Brasil. Segundo Pereira (2010, p 305), no fim do século XX, o grupo Abril era responsável por $64 \%$ do mercado brasileiro de revistas. Na década de 60 , a editora destaca-se por alcançar sucesso em suas publicações com atendimento a público diversificado e de interesses específicos, acompanhando a intensificada tendência de segmentação do mercado de revistas.

${ }^{2}$ De acordo com informações publicadas na página da Fundação Lemann (2018), há 15 anos a instituição trabalha por uma educação pública de qualidade para todos e apóia pessoas e organizações que dedicam suas vidas a solucionar os principais desafios sociais do Brasil. Define-se como uma organização familiar, sem fins lucrativos, e atua sempre em parceria com Governos e outras entidades da sociedade civil, de maneira plural e inclusiva.
} 
Embora o impresso seja uma publicação para "o estudante de Pedagogia, de Letras, do Normal e para todos aqueles que, de uma forma ou de outra, estão envolvidos com o processo de Educação do país", Civita (nº1 1986, p. 5) dirige-se, especialmente, à professora na intitulada "carta do editor" de Nova Escola. O fato do editor evocar em seu discurso a figura feminina docente, denuncia as marcas de um período histórico da educação em que a maioria dos profissionais desse setor era de mulheres e profissionalmente desvalorizadas, pois ele admite ser necessário "resgatar o prestígio" da carreira docente. Assim, Civita propõe que a revista seja uma forma de contribuição para mudar o cenário da educação pública brasileira a partir do reconhecimento da valorização dos professores e recuperação da importância desses profissionais para o país. Isso sinaliza um período de depreciação da carreira dos professores, que por infeliz coincidência perdura até os dias atuais.

Outro ponto que merece atenção diz respeito a um dos objetivos que inspiraram a criação do impresso: "fornecer à professora informações necessárias a um melhor desempenho do seu trabalho". Ao dirigir-se à leitora como portadora de informações "necessárias" para melhorar o desempenho de sua prática, Nova Escola se posiciona como aquela que garante conhecer a verdadeira realidade sobre ser professora no Brasil, por isso está disposta a fornecer a esta um tipo de conhecimento indispensável a sua prática e mudar esta realidade. A esse respeito, Silva (2002, p.39) adverte que "toda verdade e todo conhecimento não passam de ficções". Neste caso, ele se refere a ficção como sendo tudo que existe, uma vez que a ficção é a nossa verdade, aquela que construímos como uma atividade que a vida nos impele a fabricar. Sendo assim, a "realidade" que o impresso jornalístico pressupõe conhecer não passa de uma construção com aparência de real. É, pois, uma interpretação da realidade.

Observando a revista de perto, é possível percebermos que trata-se de um suporte que aproxima dois corpos teóricos - o da Comunicação e o da Educação - e dois profissionais distintos - jornalistas e professores -, mas com muita coisa em comum. São profissionais que falam para o outro, isto é, falam do que aprenderam, do que sabem, do que leram, do que viram e do que ouviram. Ambos são portadores de saberes: ao professor cabe ensinar e ao jornalista cabe informar. Ambos são percebidos na sociedade como formadores de opinião pelo conhecimento que possuem, por isso fabricam "verdades", constroem "realidades", todas a partir de interpretações que resultam de diferentes pontos de vista a depender da posição que assumem. Nesse sentido, Silva (2002) nos orienta que a interpretação é uma invenção, portanto quem interpreta não descobre a verdade, mas a produz. Portanto, pode-se compreender que verdade e realidade tratam-se de projeções, efeitos da interpretação.

Por compreender que o professor é um formador de opinião, Civita deseja integrá-lo ao processo de mudança que se acompanha no Brasil em 1986. E propõe que Nova Escola, na posição de veículo legítimo de informação, ofereça a todas as "professoras brasileiras" a troca de experiências e conhecimentos necessários a sua prática diária para que elas contribuam para a mudança esperada no país, isto é, a redemocratização da educação e da nação brasileira. Para alcançar a credibilidade das leitoras, o impresso lança mão de estratégias específicas para chegar até a professora e conquistá-la a cada edição do impresso. A linguagem utilizada para comunicar de modo pragmático sobre práticas bem sucedidas de ensino e de aprendizagem é leve e objetiva, evitando-se o "pedagogês" enfadonho. O conteúdo da revista, que trata de educação, antes de chegar ao professor, recebe tratamento jornalístico, ou seja, as reportagens, entrevistas, falas, pensamentos e opiniões dos educadores ouvidos por jornalistas, são sempre apresentados aos professores leitores segundo critérios jornalísticos, mas de uma 
maneira que não lhes causem cansaço. A organização e ordenação de um assunto e a diversidade de opiniões são pensados estrategicamente para chegar à professora de uma forma simples e atrativa, e que lhe facilite a leitura.

Assim, percebemos ainda que no discurso estrategicamente suave de Nova Escola está silenciada uma "pedagogia empreendedora" posta em prática por Victor Civita, que vê no processo de redemocratização da educação iniciado após a Ditadura Militar (1964-1985) no Brasil, no início da chamada "Nova República", a oportunidade que lhe inspira a construção de uma publicação para os professores com visão instrumental, utilitarista e pragmática da informação a serviço da educação. Tal percepção se justifica pelo discurso do editorial inaugural da revista, quando Civita ( $\mathrm{n}^{\circ} 1$, 1986, p.5) esclarece que o propósito do impresso era "fornecer à professora informações necessárias a um melhor desempenho do seu trabalho". No que diz respeito a esse fim, a afirmação que retomamos de Civita nos permite observar a cicatriz denunciadora que marca as intenções da revista: ser útil enquanto suporte de informação que veicula um saber, suas ideias de educação, de professor, de aluno e, consequentemente, de sociedade. Naquilo que se propõe a fazer, fica evidente, portanto, o convite para incluir os professores no processo de mudança que ocorria naquele momento histórico do país, afim de contribuir para uma nova realidade social: a volta da democracia brasileira e da educação para todos no país.

Ao informar o objetivo da revista é possível perceber o discurso ideológico que atravessa o dizer de Civita e constitui a maneira como o impresso percebe o professor , ou seja, este é concebido como indivíduo que não faz bem o seu trabalho porque é despreparado, mas Nova Escola é sua parceira e está para ajudá-lo nas dificuldades do dia a dia. Desse modo, o dizer de Civita tem um efeito, pois seu discurso fabrica a "verdade" de uma época, subjetivando o indivíduo e imprimindo identidade para ele. Para Gregolin (2007, p.15), "as práticas discursivas materializam as ações do sujeito na história". Assim, o sujeito é um efeito discursivo e a identidade uma construção discursiva. Logo, a relação entre o dizer e a produção de uma "verdade" pode ser compreendida como condição para uma determinação histórica. A identidade produzida para o professor e projetada para os professores leitores de Nova Escola é para que eles se convençam de que precisam de ajuda para melhorar sua prática pedagógica e contribuir para uma nova sociedade.

Assim, para integrar esse profissional "despreparado" no processo de mudança em curso, a ideia era valorizar a atuação do professor dentro da comunidade e incluí-lo em um projeto que colaborasse para aprimorar o desenvolvimento do seu trabalho. Para dar forma ao projeto editorial sonhado por Civita, o idealizador de Nova Escola propõe que o papel da revista seja o de oferecer ao professor experiências variadas e atividades diversificadas que favoreçam o bom desenvolvimento da sua prática. Esta publicação, portanto, desenvolve-se para ser vista como uma parceira do professor, ajudando-o a superar as dificuldades que atravessam o seu cotidiano, por isso o conteúdo da revista deveria ser bastante atraente, evitando-se a aridez no tratamento dos temas de seu interesse. De acordo com Revah (2013), a recusa de Civita pela dimensão pedagógica no editorial inaugural de Nova Escola, provavelmente, está vinculada a uma avaliação negativa da linguagem acadêmica presente em muitos periódicos educacionais. Nesse sentido, a revista parece pretender evitar o "pedagogês" quando enfatiza seu caráter jornalístico. A estratégia encontrada para isso decorre do facto de jornalistas escreverem para professores, evitando-se, portanto, os textos densos."A preocupação não era com a fundamentação teórica das atividades, com a divulgação de artigos de especialistas ou promover a reflexão sobre a educação brasileira" (RIPA, 2010, p. 117), 
mas a tarefa da equipe de Nova Escola era facilitar os conteúdos, evitar os textos complexos e oferecer os conceitos na sua forma prática e atrativa, de modo a inspirar o professor a alcançar bom rendimento no seu trabalho.

E assim, Nova escola toma forma configurando-se como uma realização de um antigo sonho de seu idealizador que em outrora, numa tentativa empreendedora mal sucedida de uma publicação pedagógica denominada Escola, lançada em face da conjuntura política da Ditadura Militar brasileira, foi um fracasso do ponto de vista comercial e sem alcance da esperada relevância entre os seus destinatários, os professores do $1^{\circ}$ grau, o qual correspondia ao nível de ensino criado pelo Regime Militar por meio da lei n. 5.692/71 (REVAH, 2013). Com o insucesso da revista Escola, por não conseguir penetrar no meio docente, não foi possível atingir as intenções previstas por Victor Civita em seu primeiro empreendimento pedagógico naquele momento histórico e político de seu nascimento. A revista Escola foi lançada no mês em que se comemora o dia do professor, no ano de 1971, mas não alcançou vida longa, com o número de 27 edições, teve sua publicação interrompida em abril de 1974.

Diferentemente de Escola, que teve vida breve de apenas três anos, a revista Nova Escola já completou três décadas de existência. Como suporte que "informa", "apóia" e "atualiza" o professor brasileiro, é compreendida pela FVC como um dos maiores canais de comunicação com os docentes da educação infantil e do ensino fundamental, pois ocupa o segundo lugar em tiragens, uma média de 520.000 exemplares que atinge cerca de 1 milhão de professores, segundo informações da redação de Nova Escola (2001), na página do Educabrasil. O êxito da revista que se posiciona no setor da educação como a principal revista brasileira para professores e demais responsáveis pelo processo educacional é confirmado por Civita (2008, p. 8) ao admitir que Nova Escola é " a maior revista da educação do Brasil, circula em todo o país desde março de 1986 e é uma publicação da Fundação Victor Civita". Desse modo, é possível inferir que o triunfo da revista concede a esta relações de poder, ou seja, o discurso que este suporte veicula é tomado como legítimo por grande parte do grupo de educadores, sobretudo os professores. Torna-se, portanto, fonte de referência para os professores.

Apesar do sucesso da revista, ao longo do tempo, Nova Escola sofre algumas mudanças no processo de distribuição dos exemplares. A oferta gratuita de suas edições para as escolas públicas foi encerrada em 2014. Em 2015 também foi encerrada a venda do periódico em bancas e estabelecimentos comerciais e a entrega das edições passou a ser exclusiva para os assinantes. Após conquistar milhares de leitores e leitoras em todo o país, a tradicional revista Nova Escola deixa de ser uma publicação da FVC e passa a ser uma publicação da Fundação Lemann, organização familiar sem fins lucrativos, que tem objetivos semelhante a instituição que lhe antecede no que diz respeito ao desejo de melhorar a qualidade da educação no Brasil com a parceria de professores e educadores. A Associação Nova Escola ${ }^{3}$, responsável pelas edições da revista, se define como uma "start-up da educação mantida pela Fundação Lemann e a marca mais conhecida por professores de Educação Básica no Brasil" (ASSOCIAÇÃ̃ NOVA ESCOLA, 2018).

Segundo a Fundação Victor Civita $^{4}$ (2018) em sua página na internet, a transferência da marca Nova Escola para a Fundação Lemann justifica-se em razão do desejo de dar novo impulso à revista, a fim de garantir que as publicações cresçam ainda

${ }^{3}$ Disponível em: https://novaescola.org.br/quem-somos. Acesso em 26 de mar. 2018.

${ }^{4}$ Disponível em: https://fvc.org.br/especiais/nossa-historia/ . Acesso em 26 de mar. 2018. 
mais e continuem a garantir o seu lugar no centro do debate educacional. Não obstante a mudança sofrida pelo periódico para professores, de acordo com a Associação Nova Escola, atual responsável pela revista nas versões online e impressa, a manutenção do sucesso da marca Nova Escola continua. "Temos cerca de 2 milhões de visitantes únicos por mês na nossa plataforma e cerca de 1,5 milhões de fãs no Facebook, o que nos permite conhecer bem nosso público". (ASSOCIAÇÃO NOVA ESCOLA, 2018). Tal afirmação demonstra a credibilidade e o poder da revista junto aos educadores ao representar um modelo ideal de educação para o Brasil, influenciando modos legítimos de ser professor.

\section{A vontade de verdade em Nova Escola}

Ao apresentar-se como uma publicação para professores, sem deixar de fora os demais profissionais da educação, e, ao informar que é mantida por uma instituição sem fins lucrativos, a revista Nova Escola constitui-se como uma aliada desses profissionais com o propósito de contribuir para transformar a qualidade da educação pública brasileira e reconhece na figura do professor o poder para mudar a realidade social de uma nação. $\mathrm{O}$ fato de a revista chegar aos leitores como uma produção cultural que não visa o lucro, imprime uma imagem de credibilidade para o impresso junto aos seus consumidores e intensifica a sua preocupação em contribuir para melhorias na qualidade do ensino público ofertado no Brasil em um determinado contexto histórico e social. $\mathrm{O}$ projeto editorial da revista é construído para levar ao professor saberes que podem promover um melhor desempenho do seu trabalho na prática. Logo, a proposta da revista apresenta-se como um recurso a subsidiar um profissional que parece necessitar de ajuda para fazer um trabalho interessante, que não pareça exaustivo para ele nem para o aprendiz. Nesse sentido, Nova Escola representa o suporte material do qual o professor poderá dispor para ajudá-lo a melhorar seu desempenho pedagógico e alcançar sucesso no trabalho que desenvolve com os alunos. Assim, a revista se posiciona como aquela que se esforça para oferecer um conhecimento legítimo a fim de informar o professor(a) como deve fazer o seu trabalho de uma maneira agradável, capaz de alcançar resultado positivo.

Com esse propósito, na presença da equipe para definição do Plano Editorial da revista, Victor Civita ressalta sua inquietação na Ata da reunião de criação de Nova Escola e expõe a posição que o impresso deve assumir ao chegar até seus leitores: as "Mariazinhas".

Nós temos que chegar a ela (a professora leitora de Nova Escola), simplesmente, como se fôssemos uma amiga que fala com ela em tom quente, coloquial, sobretudo afetuoso, nunca parecendo que somos superiores, que sabemos pedagogia, didática e que estamos ali para ensinar. Nada disso. Nossa tarefa será a de colocar Mariazinha, sempre, a par de um montão de coisas importantes, interessantes, agradáveis, direta ou indiretamente, ligadas ao seu trabalho e aos seus contatos com a comunidade. (Ata de reunião de 16 de setembro de 1985 cit. por LAGÔA, 1998, p. 4-5).

Como é possível perceber, a maneira como o projeto de Nova Escola é pensado pelo editor representa a idealização de uma revista delineada para projetar-se como 
amiga da professora brasileira. Numa suposta relação de parceria e amizade, o impresso precisa encantar a professora leitora e é pensada para ensinar aquilo que ela supostamente não sabe. A forma "carinhosa" como Civita se dirige à professora, chamando-a de "Mariazinha", é atravessada pela formação ideológica responsável pela imagem que ele constrói dos docentes, percebendo-os como sujeitos despreparados e com pouco prestígio social, sendo a maioria formada pelo gênero feminino. Tal percepção do que representa ser professor motivou a realização de um "velho sonho", que consiste na criação de uma revista compreendida como parceira do professor e da educação.

Em contextos político e social diferentes, constatamos nas duas edições selecionadas para análise neste estudo, que o impresso conserva o perfil de revista delineado por Civita no seu projeto editorial, pois a revista porta-se como parceira da educação e aliada do professor brasileiro. Nova Escola continua a se esforçar no propósito que lhe constitui, conforme podemos perceber no discurso da então editora, na intitulada "Carta ao leitor".

Esta edição, como você verá, significou, também, um tremendo esforço de reportagem dos nossos jornalistas, que empreenderam uma verdadeira maratona para cobrir as propostas pedagógicas desenvolvidas em escolas de 10 diferentes Estados brasileiros: do arquipélago do Bailique, a 14 horas de barco de Macapá (AP), foram a Leoberto Leal, cidade distante $130 \mathrm{Km}$ de Florianópolis; de Gama, a $45 \mathrm{Km}$ de Brasília, chegaram a Foz do Iguaçu, fronteira do Brasil, Argentina e Paraguai, situada a 637 Km de Curitiba; de dois Córregos, a $223 \mathrm{Km}$ da capital paulista, atingiram Ouro Preto, em Minas Gerais; de Goiânia (GO) foram a Porto Alegre, Recife e Rio de Janeiro (FIORE, 1998, p.3).

Nova Escola, representada na figura dos jornalistas, é sinônimo de esforço e dedicação para levar ao professor inspirações que auxiliem a melhoraria de sua prática em sala de aula e, em consequência, a melhoria também da qualidade do ensino público brasileiro. É, portanto, uma colaboradora do professor nas suas atividades de ensino. $\mathrm{O}$ contexto no qual se constitui tal efeito de sentido é marcado pelo empenho dos jornalistas em percorrer diferentes Estados brasileiros para produzir

matérias divertidas, como a da alfabetização por meio dos sentidos; curiosas, como a que compara a digestão humana com a da galinha; instigantes, como a do cálculo mental; inusitada como a da escola que nasceu da mata; e ricas, como a matéria de capa - um completo curso de alquimia que permite criar sofisticados materiais para aulas de Arte, a custos de fato irrisórios (FIORE, 1998, p.3).

O contexto político da educação brasileira, que compreende tal edição de Nova Escola, é marcado pelo final do primeiro governo de Fernando Henrique Cardoso. Neste governo a educação básica é evidenciada, sobretudo nos documentos legais que são aprovados, implementando mudanças na política educacional do Brasil. Na legislação da educação, as mudanças acontecem desde a aprovação da nova versão da 
Lei de Diretrizes e Bases da Educação Nacional - LDB 9394/1996, a lei maior da educação, aos Parâmetros Curriculares Nacionais - PCNs.

$\mathrm{O}$ cenário de reforma na educação brasileira no governo $\mathrm{FHC}$, representa o propósito do movimento internacional encaminhado pelo Banco Mundial que vê no Brasil o terreno fecundo para instaurar as suas ideias para a educação. Nesse sentido, esta instituição internacional passa de emprestador de dinheiro a formulador de políticas para o país. Por razões de limites neste artigo e também por não se tratar de objeto de estudo neste trabalho, não será possível discutir os detalhes sobre as mudanças trazidas a educação brasileira pelos documentos implantados na reforma da educação. Buscou-se fazer uma alusão histórica para situar o contexto político da educação brasileira no período de publicação do impresso em análise.

Observamos que, apesar das políticas de mudanças implantadas pelo governo FHC para melhorar a educação brasileira, a ação não produziu grandes efeitos, tendo em vista que a situação da educação pública ainda clama por melhoras, por isso "a revista do ensino fundamental" continua se esforçando para oferecer aos professores referências de boas propostas pedagógicas para estimular a prática desses profissionais no exercício da docência. "Esperamos que você ache estimulante o resultado" Fiore (1998, p3). O discurso editorial de Nova Escola denuncia que o ensino público do Brasil continua a precisar de melhorias e que o problema da qualidade pode ser revertido positivamente através de ações que incentivem o bom desempenho docente. Fica subentendido, portanto, a ausência de elementos motivadores de uma boa prática no cotidiano docente. Para contornar essa lacuna da educação, o impresso seria uma forma de estímulo a contribuir para o aprimoramento dos professores.

Nessa perspectiva, a formação docente tem um peso na qualidade do ensino. Quando bem sucedida, é essencial para o avanço do desempenho dos alunos. Mas enquanto permanecer distante da realidade escolar, seguirá contribuindo para a manutenção das desigualdades sociais. No governo do presidente Luis Inácio Lula da Silva - Lula, a preocupação com o professor e sua formação teve mais ênfase que no governo FHC, o qual lhe antecede. Em entrevista a revista Nova Escola (2008), o ministro da Educação, Fernando Haddad, fala sobre a formação de professores da educação básica como a prioridade do Ministério da Educação no governo Lula. Haddad cita a criação do Sistema Nacional de Formação do Magistério - Lei $\mathrm{n}^{\circ}$ 11.502/2007, que atribui à Coordenação de Aperfeiçoamento de Pessoal de Nível Superior (Capes) a responsabilidade pela formação de professores da educação básica. O objetivo dessa atribuição é garantir a qualidade da formação dos profissionais que já estão em exercício ou que ainda atuarão nas escolas públicas, visando à qualidade do ensino público.

Apesar de não ser uma temática inédita, é bastante relevante trazer o professor para o centro das discussões em educação, tendo em vista que os problemas com a qualidade do ensino no Brasil caminham sem solução, mesmo tendo sido assunto presente na pauta de diferentes governos no país, como foram nos governos FHC e Lula, por exemplo. Em contexto de governo marcado por melhorias sociais com avanços na economia e inclusão social, o então presidente Lula não conseguiu avançar o suficiente na educação para solucionar o problema da qualidade do ensino público no país. Apesar de todo esforço do governo para mudar a realidade da educação pública, Lula conclui seu mandato conseguindo melhorias importantes para o setor, mas ainda distante de ser o bastante. Por se tratar de um assunto complexo e por inspirar preocupação, o problema da qualidade do ensino público no Brasil é concentrado por Nova Escola na formação do professor e torna-se tema para discussão na revista 
selecionada para análise.

A pedido de NOVA ESCOLA, a Fundação Carlos Chagas analisou os currículos dos cursos de Pedagogia e concluiu que, de fato, eles não preparam os futuros educadores para a realidade escolar (GROSSI, 2008, p.8).

Desde o surgimento de Nova Escola, o impresso aponta para a necessidade de preparar melhor o professor para a sua prática. Passam-se 22 anos e o problema da formação docente persiste. Ao contratar a Fundação Carlos Chagas para analisar os currículos e saber sobre o foco que é dado ao ensino para crianças pelos cursos de Pedagogia, constata-se que este é um curso genérico e que não dá ênfase às competências de sala de aula, distanciando-se da realidade dos alunos. Os resultados da pesquisa possibilitam a compreensão de que os professores não são devidamente habilitados para ensinar o que de fato é necessário dentro de uma realidade escolar. Observamos que esta "verdade" sobre o ensino público brasileiro é determinada pelo poder institucional que é conferido a Fundação pelo saber que possui sobre o fator currículo e sobre a educação no Brasil. A "verdade" é disseminada por Nova Escola a partir da conclusão de uma autoridade. A instituição escolhida por Nova Escola para analisar os currículos dos cursos de Pedagogia tem autoridade para construir verdades, tendo em vista a posição de confiabilidade que ela assume no desenvolvimento de pesquisas educacionais no Brasil. Logo atua no âmbito da legitimidade científica, pois o saber construído sobre os cursos de Pedagogia constitui o solo de formação da verdade.

De acordo com a leitura realizada da obra de Foucault, A ordem do discurso, as verdades científicas são o resultado do desejo de saber. A hipótese genealógica é a de que aquilo normalmente denominado como verdade constitui efeito da vontade (histórica) de verdade observada na articulação entre estratégias de poder e tecnologias de saber (CANDIOTTO, 2013, P.50). Compreende-se que o resultado da pesquisa reconhecida e disseminada por Nova Escola como verdadeira é atravessada por uma vontade de verdade de dizer esse discurso verdadeiro. Trata-se, pois, daquilo que Foucault (2009) reconhece por justificação racional de sistemas excludentes de poder que atuam nas práticas institucionais e científicas, tais como na pesquisa e na informação.

Ao informar que os cursos de Pedagogia não oferecem aos futuros professores o devido preparo para o exercício da docência, Nova Escola se posiciona como portadora de uma verdade, apoiada no resultado conferido por uma instituição legítima que desenvolve um conjunto de práticas, as quais separam o verdadeiro daquilo que supostamente é falso. Nesse contexto, a "verdade" atribuída ao professor é a de que ele é despreparado para o exercício da docência e isso justificaria o baixo rendimento dos seus alunos. Sabendo do peso que seria para o professor receber tal informação sobre ele e o seu trabalho, o impresso faz uso de uma linguagem polida e prefere atribuir ao professor a identidade de protagonista do ensino, enfatizando a importância desse profissional no processo de ensino-aprendizagem.

É um trabalho de fôlego, que ajuda a dar a verdadeira importância que tem o professor como protagonista do processo de ensino aprendizagem - e mostrar que ainda há muito a avançar para melhorar o desempenho de nossos alunos (GROSSI, 2008, p. 8).

É importante destacar a alusão que a revista faz sobre o seu esforço para oferecer ao leitor, o resultado da apuração da pesquisa que rendeu uma entrevista com o ministro da educação e um dossiê com 14 páginas. Observamos que nas duas edições 
selecionadas para análise, o texto editorial da revista põe em evidência o seu esforço para levar informação ao professor. Tanto esforço e dedicação justifica-se pela condição de parceira e amiga do professor que o impresso parece assumir.

$\mathrm{Na}$ edição de 2008, a qual nos referimos na última citação, o que estamos a afirmar pode ser compreendido pela escolha do uso da expressão "trabalho de fôlego", já na edição de 1998, observamos tal ocorrência explicitamente por meio da expressão "tremendo esforço" e também através do substantivo "maratona". Tal expressão e substantivo são constitutivos do discurso editorial do impresso com a afirmação de que "Esta edição (...) significou um tremendo esforço de reportagem dos nossos jornalistas, que empreenderam uma verdadeira maratona (...)" (FIORE, 2008, p.3). Nota-se mais uma vez a vontade de verdade de Nova Escola ao confessar para os professores leitores o grau de esforço dos jornalistas para produzir reportagens motivadoras para os docentes. A empreitada jornalística confere efeito de verdade para o impresso que informa o leitor sobre uma realidade construída.

Compreendemos a confissão editorial e as técnicas de saber dos jornalistas como mecanismos de poder que induzem e tornam possíveis as produções de verdades na medida em que buscam legitimação racional que justificam não só o esforço e toda dedicação do impresso para informar o leitor, como também apoiam de forma legítima a interpretação sobre a necessidade de melhorar a qualidade do desempenho docente. Assim, observamos que o discurso de Nova Escola é atravessado por uma vontade de verdade que identifica o professor na figura daquele que precisa ser melhor preparado para alcançar bom desempenho com os escolares. A prática da confissão editorial qualifica como verdadeiro todo esforço e colaboração da revista para auxiliar o professor nesse feito.

No entanto, é preciso ressaltar que na edição de 2008 o impresso faz uso de um discurso polido para valorizar a importância do professor no processo de ensinoaprendizagem, uma vez que não parece nada leve informá-lo sobre o peso da sua formação. A edição de 1998 segue a mesma linha discursiva de valorização do trabalho docente, porém a polidez é dispensada ao discurso do impresso, tendo em vista a leveza do conteúdo informativo que destina-se a narrar sobre práticas pedagógicas bem sucedidas desenvolvidas por professores de 10 diferentes estados brasileiros. A leveza da informação é estampada na capa do impresso com o sorriso da professora Zuleica, em contrapartida, o peso do conteúdo é representado pela cor negra das peças de dominó que ilustra a capa da revista e informa sobre a formação docente. As capas do impresso selecionadas para análise confirmam na próxima seção os pontos sinalizados até aqui e ainda apresentam outros. Observam-se as estratégias discursivas no jogo do poder das capas de Nova Escola para a construção de identidades para o professor.

\section{O jogo estratégico do poder nas capas da revista Nova Escola}

Desde o princípio de criação até a atualidade, a maior revista de educação do Brasil se apresenta como aquela que tem um conhecimento especial sobre como fazer para transformar e melhorar a qualidade da educação pública brasileira. Isso nos leva ao encontro das reflexões foucaultiana acerca da sujeição da subjetividade como efeito da articulação entre mecanismos de poder e técnicas de saber que, associados, estabelecem 
a produção da verdade ${ }^{5}$ sobre o sujeito. Assim, não há como deixar de considerar as relações de poder estabelecidas por Foucault no processo de subjetivação, pois isso implicaria "o abandono da via de conhecer o sujeito moderno" (Fonseca, 2013, p.30). A estratégia genealógica, de que trata Foucault, pretende evidenciar o poder a partir de uma visão ampliada, que distancia-se da concepção de poder como uma coisa que domina e se aplica aos indivíduos pela relação de ordem e obediência, mas ao contrário disso, o filósofo destaca o poder como algo que circula pelos indivíduos, garantindolhes a possibilidade tanto de exercê-lo como de serem sujeitos a ele. Dito de outro modo, só há relações de poder com sujeitos livres, pois, "onde existe violência, escravidão e domesticação, inexistem relações de poder e resistências" (CANDIOTTO, 2013, p. 90). Na abordagem foucaultiana a resistência configura-se como uma estratégia do poder enquanto possibilidade de liberdade. "O que faz com que o poder se mantenha e que seja aceito é simplesmente que ele não pesa só como uma força que diz não, mas que de fato ele permeia, produz coisas, induz ao prazer, forma saber, produz discurso" (Foucault, 1979, p.8). Ao produzir discursos, o poder também opera na produção de identidades para os sujeitos através de enunciados qualificados como verdadeiros.

Sendo assim, ao fazermos uso das lentes de aumento foucaultiana para observarmos a revista Nova Escola, a enxergamos como um objeto de poder capaz de produzir discursos verdadeiros que subjetivam e identificam os indivíduos, tanto pela aceitação quanto pela contingência de resistência aos modos de dizer da revista. Embora a estratégia de Nova Escola seja a de posicionar-se como possuidora de um saber sobre práticas de ensino e sobre ser professor, por isso prontifica-se a informar seus leitores sobre esse domínio, há que se considerar a possibilidade de resistência de alguns de seus leitores quando não aceitam a "verdade" produzida pela revista sobre o domínio da educação, pois os indivíduos não lhe devem obediência uma vez que pelo método arqueológico trabalha-se com sujeitos livres que têm diante de si um leque de possibilidades em que diversas condutas, diferentes reações e variadas formas de comportamentos podem acontecer. A liberdade é, pois, condição de existência das relações de poder.

Na concepção foucaultiana, o poder

deve ser analisado como algo que circula, ou melhor, como algo que só funciona em cadeia. Nunca está localizado aqui ou ali, nunca está nas mãos de alguns, nunca é apropriado como riqueza ou bem. $\mathrm{O}$ poder funciona e se exerce em rede. Nas suas malhas os indivíduos não só circulam, mas estão sempre em posição de exercer este poder e de sofrer sua ação. (FOUCAULT, 1979, p.183).

Ao tomarmos as considerações enunciadas por Foucault, fica evidente que a questão do poder implica relações entre pessoas, logo não é algo instável, mas transitório, reversível, possibilitando a qualquer um exercer e sofrer suas ações, quando se tem em vista que não há um dono do poder, mas o que há são situações estratégicas que implicam relações de poder, as quais perpassam os indivíduos e os constituem. As relações de poder também auxiliam as práticas identitárias na dinâmica social, uma vez que a identidade é um efeito discursivo permeado de poder. Na perspectiva das questões do poder, Foucault (1979, p.183) ainda reitera que, "efetivamente, aquilo que faz com

${ }^{5}$ De acordo com Foucault (1979, p. 13), a verdade é "o conjunto das regras segundo as quais se distingue o verdadeiro do falso e se atribui ao verdadeiro efeitos específicos de poder". 
que um corpo, gestos, discursos e desejos sejam identificados e constituídos enquanto indivíduos é um dos primeiros efeitos do poder". Ao considerar que a subjetividade é, simultaneamente, tanto um efeito do poder quanto o "centro de transmissão" do poder, conforme compreende Foucault (1979), tomaremos duas edições da revisa Nova Escola para análise do processo de identificação e constituição do sujeito e das relações de poder.

O corpus de análise para este trabalho é constituído por duas capas de dois exemplares distintos da revista, ambos do mês de outubro, sendo um exemplar do ano de 1998 e o segundo exemplar do ano de 2008, definindo o período temporal para análise - uma cronologia de dez anos -, a partir da comparação entre duas edições (116 e 216) de Nova Escola. O discurso materializado nas capas da revista nos fará compreender a correlação entre identidade e relações de poder, mais precisamente, possibilitará compreendermos como a identidade docente é construída enquanto efeito de poder nas duas edições de Nova Escola.

As leituras que fizemos dos estudos foucaultianos, nos permitiu perceber o lugar de onde enuncia a revista, se posicionando como aquela que sabe o que diz e, por isso, lhe é concedido o poder de informar aos professores leitores o que eles precisam saber para tornarem-se sujeitos de ensino qualificados e preparados para o trabalho. Assim, Nova Escola destaca-se como um instrumento capaz de incentivar, induzir e produzir objetos, discursos de verdade. O jogo estratégico do poder pode ser conferido nas capas da revista.

FIGURA 1 - A Maga revela suas fórmulas

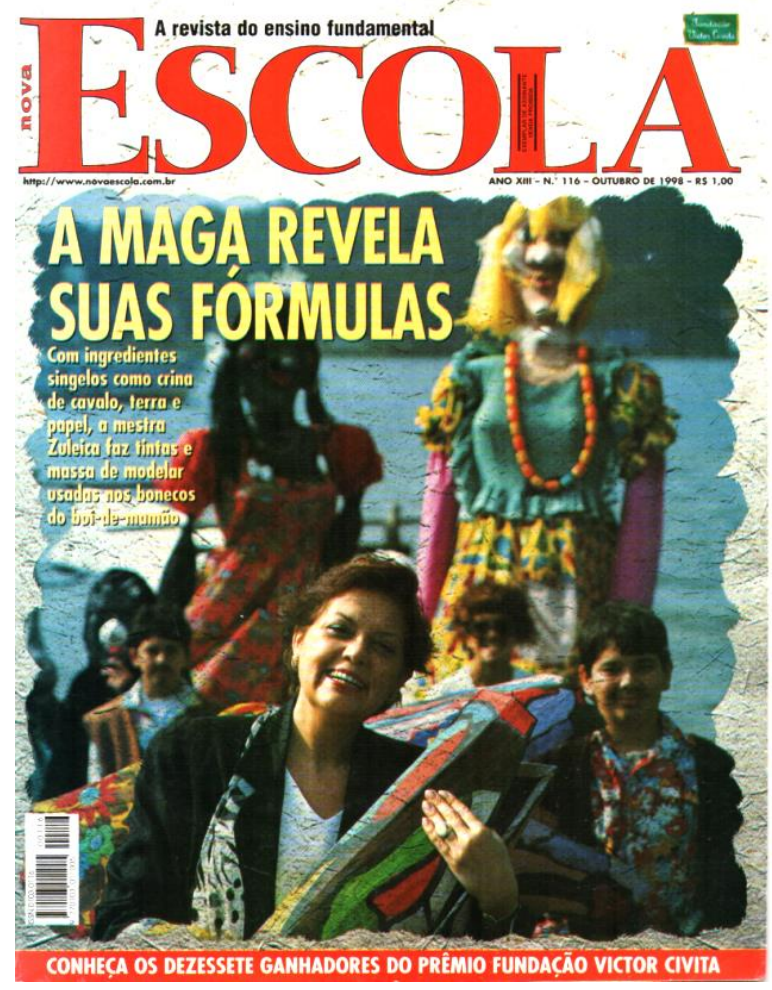

Fonte: Nova Escola. A revista do ensino fundamental, Fonte: Nova Escola. A revista de que educa. $\mathrm{n}^{\circ}$ 216,

nº116. 1998.
FIGURA 2 - Efeito dominó

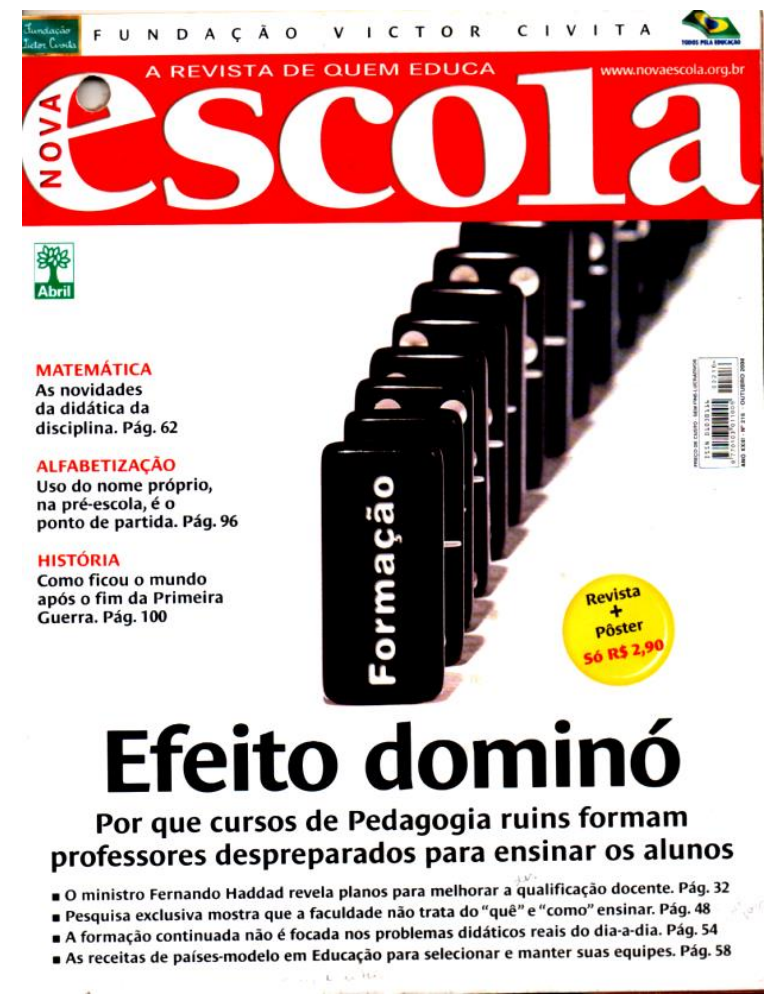

2008. 
Ao olharmos para as capas de Nova Escola pela perspectiva foucaultiana, percebemos uma produção atravessada pela memória que se materializa no discurso. Ambas as capas remetem, de uma forma ou de outra, à noção de memória. O sentido estabelecido no discurso representado tanto na figura 1 quanto na figura 2 decorre da relação de paráfrase que a palavra "Maga" e a expressão "Efeito dominó" mantém com o enunciado no interior de uma matriz de sentido que se organiza no contexto de uma formação discursiva ${ }^{6}$.Tal relação consiste numa operação em que uma palavra ou expressão retoma outras, possibilitando determinados efeitos de sentidos, pois "a matriz de sentido estabelece o que pode e deve ser dito [grifo do autor] no interior de uma formação discursiva". Isso sinaliza que há sentidos que não podem ser produzidos, estabelecendo um limite instituído através do processo de repetibilidade (Indursky, 2011, p. 68).

O jogo de repetições discursivas são produzidas nas capas de Nova Escola e podem ser percebidas pelas palavras "Maga" e "fórmula" na figura 1, cujo sentido produzido remete a uma espécie de feiticeira moderna com poder para curar o mal da educação brasileira, bem como seduzir o outro através do saber que possui, representado pelo ritual de trabalho com ingredientes simples do cotidiano. Tal efeito de sentido é resultado da operação semântica que encontra eco na literatura e no cinema, os quais trazem em seus textos bruxas e feiticeiras como personagens que usam o poder da magia para transformar uma realidade. Na saga Harry Potter, que trata demasiadamente sobre o assunto de magia, por exemplo, o pequeno Harry perde os pais e segue sua rotina em uma escola preparatória para bruxos, na qual aprende o poder da magia e como deve usar os ensinamentos para o bem. Nova Escola, portanto, parece posicionarse como sendo esse "lugar mágico" onde os professores leitores podem buscar os ensinamentos necessários para mudar as ações pedagógicas que envolvem o processo de ensino e assim alcançar efeito positivo.

Nessa perspectiva, Orlandi (2009, p. 54) esclarece que "o interdiscurso memória discursiva - sustenta o dizer em uma estratificação de formulações já feitas mas esquecidas e que vão construindo uma história de sentidos". Assim, na figura 2, a expressão "Efeito dominó" remete a uma operação que sinaliza fronteira entre algo que veio de outro lugar, o pré-construído, e o que foi produzido pela revista. A expressão que estampa o centro da capa do periódico para professores é normalmente empregada em relação a outras situações de comunicação, mas no discurso de capa é utilizada para especificar o que se diz e autoriza a compreensão de que a formação docente é determinante para o (in)sucesso escolar dos estudantes e funciona como efeito em cadeia para o bem ou para o mal. Tal efeito de sentido é assegurado por elementos provenientes do interdiscurso inscrito no discurso de capa de Nova Escola. Nesse sentido, Indursky (2011, p. 70) admite que "o sujeito, ao produzir seu discurso, o realiza sob o regime da repetibilidade, mas o faz afetado pelo esquecimento, na crença de ser

\footnotetext{
${ }^{6}$ No caso em que se puder descrever, entre um certo número de enunciados, semelhante sistema de dispersão, e no caso em que entre os objetos, os tipos de enunciação, os conceitos, as escolhas temáticas, se puder definir uma regularidade (uma ordem, correlações, posições e funcionamentos, transformações), diremos, por convenção, que se trata de uma formação discursiva (Foucault, 2010, p. 43).
} 
origem daquele saber". Isso nos leva a pensar no perigo de entrar na ordem do discurso advertida por Foucault (2009) tendo em vista os poderes que pesam sobre aquele que diz.

Assim, ao observarmos as capas de Nova Escola à luz da teoria foucaultiana, constatamos uma produção construída a partir do discurso-outro, que se entrecruza no discurso da revista, concedendo-lhe poder para dizer um discurso que visa a descrição do real e autoriza efeitos de verdade. Nesse sentido, observamos a realização de práticas discursivas constituídas pela ideia de estimular e encorajar o professor a transformar a sua prática a partir do uso de materiais simples e situações didáticas reais como faz a professora Zuleica na figura 1. "A Maga revela suas fórmulas com ingredientes singelos como crina de cavalo, terra e papel, a mestra Zuleica faz tintas e massa de modelar usadas nos bonecos do boi-de-mamão". Neste enunciado, a professora, representada na figura de uma feiticeira, confidencia à Nova Escola a sua fórmula de sucesso para alcançar a posição de profissional preparada e bem sucedida, que garante um ensino de qualidade para os alunos. Dessa maneira, a revista enuncia do lugar daquela que conhece o segredo da fórmula mágica do ensino porque lhe foi confessado pela professora "feiticeira", o que confere a revista poder para informar ao leitor sobre um saber legítimo com o propósito de incentivá-lo a tornar-se também um feiticeiro do ensino, preparado para transformar a sua prática.

Nesse sentido, de acordo com Romeu (2012, p. 57), "há uma relação constante entre saber e poder, pois aquele não existe sem este e ambos constituem a 'verdade' que, por sua vez subjetiva e constrói identidades para os sujeitos". Nota-se, portanto, a estratégia discursiva da revista. Ela se apóia no trabalho da professora Zuleica, a quem considera uma "Maga", mostrando que conhece os segredos para trabalhar com os alunos e está disposta a contá-los aos professores leitores, a fim de que eles aprendam o mistério e ponham em prática nas suas turmas, em sala de aula. Ao fazer isso, a revista mantém consigo o poder de produzir um discurso verdadeiro, aceito por uma maioria de leitores, induzindo-os a serem feiticeiros como é a professora Zuleica quando está em sala de aula com seus alunos.

Ao observarmos a segunda capa de Nova Escola na figura 2, percebemos o destaque que é dado para a formação de professores. Dentre os vários fatores que influem a qualidade da escola, o professor é apontado pela revista como a peça principal do "jogo" e sua formação faz toda a diferença na condução e no resultado desse jogo, seja ele bom ou mau. Pelas evidências construídas pelo impresso para educadores, entre eles os professores, o resultado do Brasil é negativo. A capa apresenta a imagem de um jogo de dominó de modo que cada peça parece representar um fator que contribui para o (in)sucesso escolar e, nesse jogo, a peça que representa o professor é destacada pelo substantivo "formação", o qual colabora para o processo de subjetivação do sujeito professor, isto é, o indivíduo está sujeito aos efeitos do poder da formação docente subjetivando-o e identificando-o em sujeito preparado ou despreparado para lecionar. No caso do Brasil, na edição 216 de Nova Escola (figura 2), o professor é identificado como sujeito despreparado para o trabalho docente. 
$\mathrm{Na}$ estratégia discursiva da capa do impresso para educadores, as peças do dominó aparecem arrumadas de tal forma que lembra o movimento de um tombo em cadeia, uma sobre as outras. Essa representação metafórica funciona para representar a qualidade de educação, sobretudo, a educação brasileira, que de acordo com a revista não caminha bem. A imagem sugere que assim como no dominó, é necessário iniciar com uma "partida" que estabelece todo o processo do "jogo": a formação inicial dos professores. Quando ela é boa, todos ganham, quando não é, todos perdem como uma reação em cadeia.

Conforme é possível perceber, a imagem do dominó dialoga com o enunciado verbal que constitui a capa de Nova Escola e juntos constroem a vontade de verdade de um período sobre o professor e sobre a qualidade do ensino brasileiro. A expressão "Efeito dominó" que aparece em destaque na cor preta no centro da capa da revista, realça o sentido de que o insucesso escolar do Brasil tem origem na formação docente que não prepara o professor para a atividade de lecionar. Como efeito em cadeia, a falha na formação docente reflete na qualidade do ensino ofertado pelos professores nas escolas brasileiras. Para alcançar o efeito de legitimidade naquilo que enuncia, a revista ainda traz no centro da capa o questionamento "Por que cursos de Pedagogia ruins formam professores despreparados para ensinar os alunos" e, em seguida, aponta justificativas para o porquê da questão. As justificações podem ser encontradas no interior da revista, nas páginas indicadas na capa de Nova Escola, que estrategicamente apóia-se em discursos de autoridades como o ministro da Educação Fernando Haddad e pesquisa exclusiva da Fundação Carlos Chagas para alcançar o efeito de verdade pretendido pelo periódico educacional. De acordo com Navarro (2010, p. 86), "as estratégias de construção de efeito de realidade funcionam como índices de referencialidade que conferem aos discursos um caráter verossímil, assegurando-lhes a credibilidade.

Assim, a "verdade" é produzida por efeitos regulamentados do poder, tendo em vista "como o saber é aplicado em uma sociedade, como é valorizado, distribuído, repartido e de certo modo atribuído" (FOUCAULT, 2009, p.17). O verdadeiro é, pois, uma construção discursiva regulada por mecanismos de controle do discurso que autorizam o que pode e o que deve ser dito em um determinado lugar. O discurso das capas de Nova Escola é atravessado por vozes que autorizam a legitimidade de enunciados verdadeiros, regulados por mecanismos que estabelecem o quê e o como é possível dizer em determinado espaço enunciativo. Ao compararmos as duas capas da revista, observamos sujeitos de uma mesma categoria da educação, que desempenham a mesma função, mas que assumem identidades distintas nas capas do impresso para educadores: na figura 1 é construída uma imagem positiva para o professor, já na figura 2 o professor é constituído por uma imagem negativa que o identifica como profissional despreparado e desqualificado, isto é, à margem da ordem do ensino.

A falta de qualificação docente é apontada pelo impresso por meio do discurso indireto, a partir da afirmação de uma autoridade política com poder para dizer pois, "o ministro da Educação Fernando Haddad revela planos para melhorar a qualificação 
docente." Se há planos para melhorar a qualificação dos professores, evidentemente, esses profissionais são reconhecidos pelo ministro e pela revista como sujeitos desqualificados para o ensino. Assim, a identidade docente constitui-se, portanto, na forma de sujeição aos efeitos do poder, estabelecida pela relação entre sujeito e discurso. Para efeito de ratificar o que estamos a afirmar, a mesma edição da revista representada na figura 2, confirma o despreparo e a falta de qualificação docente ao enunciar que "a formação continuada não é focada nos problemas didáticos reais do diaa-dia". Simultaneamente, ao questionar sobre a formação docente, a revista apresenta uma afirmativa atravessada na problemática que ela propõe ao interpelar "por que cursos de Pedagogia ruins formam professores despreparados para ensinar os alunos". Assim, Nova Escola admite o despreparo dos professores e desqualificação não apenas desses, mas também dos cursos de formação de professores que não preparam efetivamente o docente para o trabalho de planejar, ensinar e avaliar.

A revista ainda admite a falta de preparo docente para desenvolver um trabalho didático a partir de situações reais do cotidiano. Esses acontecimentos discursivos demonstram a posição ideológica assumida pela revista, que embora busque, ilusoriamente, ser imparcial, acaba por estabelecer um ponto de vista, já que não há possibilidade de um discurso neutro, pois a ideologia é a condição necessária para a construção do sujeito e dos sentidos (ORLANDI, 2009). Desse modo, a capa da edição 216 denuncia a necessidade de investimentos na formação docente como prioridade a fim de garantir um ensino satisfatório que transforme o resultado da qualidade da educação no país.

Ao compararmos as capas, percebemos que o discurso de ambas as edições prescrevem modelos de práticas efetivas ao revelar "fórmulas" e "receitas" que parecem garantir um ensino de qualidade com profissionais preparados, ou seja, na ordem do ensino. As marcas de autoria da revista podem ser observadas pela estratégia discursiva de dizer a partir da voz do outro com vista a produzir uma verdade e alcançar credibilidade naquilo que enuncia. Portanto, o discurso "verdadeiro" de Nova Escola aufere o efeito de legitimidade pelo discurso indireto, distanciando-se do que diz, na tentativa de ser imparcial quando informa sobre conteúdos pedagógicos. Produzir textos imparciais e objetivos, que não exponham opiniões, mas fatos para que o leitor tire suas próprias conclusões, marca uma estratégia da escrita midiática para promover o efeito de realidade. A respeito da ordem discursiva da mídia impressa, Navarro (2010, p.82) afirma que "os discursos, invariavelmente, empregam procedimentos cuja finalidade é a de garantir e a de solidificar sua legitimidade perante a comunidade que os recebe".

Curiosamente, no intervalo de 10 anos a revista mostra os dois lados da moeda da educação: um lado estampado com a face positiva do professor, o outro com sua face negativa. A linha do tempo representada pelas duas capas do impresso possibilita-nos perceber o professor no centro do discurso sobre educação e a formação docente como a palavra chave para a problemática do insucesso escolar no Brasil. Enquanto a edição do ano de 2008 (figura2) da revista emoldura a má qualificação profissional dos professores brasileiros, subjetivando-os e identificando-os como indivíduos 
despreparados e desqualificados, a edição de 1998 (figura1) faz veicular uma imagem satisfatória do ensino e do ser professor sempre almejada pela revista desde o princípio da criação do impresso, que tem finalidade comunicativa de informar os professores leitores sobre a prática profissional do magistério. Nota-se, portanto, que os discursos das capas constroem identidades para o professor cuja interpretação é possibilitada pelo conjunto de vozes enunciativas que atravessam e autorizam a prática discursiva de Nova Escola.

Conforme é possível observarmos, ao retomarmos para análise a capa da revista representada na figura 1, a professora feliz e sorridente estampa a capa do impresso Nova Escola. O sorriso da professora Zuleica parece representar a satisfação de uma profissional realizada ao lado dos seus alunos. O modo como ela segura nas mãos uma parte do boneco que ensina os alunos a construir com materiais simples, encontrados no dia a dia, traduz a dedicação e o contentamento de uma profissional que desenvolve seu trabalho com prazer. Ao enunciar que Zuleica consegue produzir o próprio material de trabalho com "ingredientes singelos", a revista revela-se um instrumento capaz de induzir, influenciar os professores leitores, no sentido de dirigir suas condutas, subjetivando-os e identificando-os como verdadeiros mestres, uma espécie de alquimistas da educação. No contexto de profissional dedicada, a professora Zuleica assemelha-se com a "Mariazinha" concebida por Victor Civita na definição do plano editorial da revista, porém no que se refere ao preparo profissional, a docente é o oposto da "Mariazinha da Silva" imaginada pelo idealizador de Nova Escola. "A nossa Mariazinha da Silva, como você sabe não tem muito preparo, provavelmente muita cultura, mas é extremamente dedicada ao seu trabalho" (CIVITA, 1985 cit. por LAGÔA 1998). De certa forma, o discurso de capa dialoga com o dizer de Civita, pois evidencia uma profissional comprometida, dedicada e preparada o suficiente para desenvolver, efetivamente, o seu trabalho por meio da criatividade e competência, fazendo uso de objetos simples que tornam a aula um momento interessante para as práticas de ensino e aprendizagem. A professora Zuleica, portanto, representa, em parte, a imagem docente idealizada no projeto editorial da revista, porém a criatividade e sua competência não correspondem as características da "Mariazinha da Silva".

A imagem de professor despreparado é construída na edição 216 (figura 2) por meio da má formação docente inicial e continuada dos profissionais, que justifica a qualidade do ensino no Brasil. O discurso de capa movimenta o sentido de que há uma lacuna na formação do professor que necessita ser preenchida para mudar a realidade do ensino brasileiro e Nova Escola se posiciona como um recurso que poderá auxiliar o professor nessa situação com ideias simples e eficazes, conforme observa-se na edição 116 através das "fórmulas" reveladas pela "Maga": a professora Zuleica. Ao comparamos as duas edições da revista, constatamos um jogo discursivo estratégico e ideológico que leva a revista a se posicionar para evidenciar a falta de qualidade do ensino e o insucesso escolar que parecem poder ser contornados com a contribuição das sugestões e orientações oferecidas por Nova Escola. Desse modo, constatamos que há um desejo desse impresso de ser aceito e reconhecido pelos professores leitores como 
objeto indispensável ao profissional da educação, pois os slogans que identificam o impresso confirmam nossa constatação ao posicionar-se como "A revista do ensino fundamental" (figura 1) e "A revista de quem educa" (figura 2). O determinante representado pelo artigo definido "a" que antecede o substantivo "revista", concede ao periódico o sentido de pioneira dos professores, mostrando-se como referência para tratar das questões de ensino e de aprendizagem.

Observa-se, portanto, que no período de uma década a revista é identificada por slogans distintos, porém a cicatriz ideológica que atravessa e marca o seu discurso permanece, não sofre alteração. Nova Escola posiciona-se desde o princípio e continua assumindo a posição de revista precursora com expressiva aceitação dos professores leitores, como aquela que simultaneamente dá voz aos anseios docentes e busca mensalmente acalmá-los, dando-lhes sugestões e orientações para solucionar os problemas da aprendizagem na sala de aula. Nesse sentido, o discurso de capa desse impresso para professores busca convencê-los de que em suas páginas os professores encontrarão a receita - como se ela existisse - para solucionar as dificuldades de aprendizagem localizadas no interior da escola. Sendo assim, não podemos deixar de ratificar a nossa percepção de que a revista conduz o professor leitor a acreditar que os problemas da aprendizagem tem origem no professor, ou seja, resume-se a falta de preparo profissional decorrente de uma formação inadequada, que não trata do quê e como ensinar. Por isso, Nova Escola está para suprir esta lacuna com ideias para incentivar o professor a melhorar sua prática.

\section{Considerações finais}

Ao apontar o professor e os cursos de formação como os responsáveis pelo baixo desempenho da aprendizagem dos alunos, a revista cria uma imagem distorcida do educador, pois silencia e não permite ao leitor perceber que a suposta "incompetência" do professor não decorre exclusivamente de cursos de Pedagogia ruins que formam mal educadores, mas a "incapacidade" docente pode ser justificada como o resultado de um processo de escolarização mal sucedido, reflexo de um sistema que não valoriza a profissão docente.

Logo, um sistema escolar que não trata o professor como prioridade, produz centenas de professores "incapazes" e que certamente produzirá outras centenas de alunos que não aprendem, como um efeito em cadeia que se inicia no ensino fundamental e não no ensino superior como evidencia e tenta convencer o discurso de capa de Nova Escola. A falta de investimentos em políticas públicas na educação é outro fator que contribui para a baixa qualidade do ensino brasileiro, mas essa informação não é assinalada por Nova Escola. Nota-se, portanto, um silenciamento discursivo bastante significativo no que se refere à construção da identidade docente. Ao formular um determinado enunciado, Nova Escola silencia outros sentidos possíveis, mas não desejados naquele momento. Trata-se de um silêncio constitutivo, tratado por Orlandi (2007) como silêncio político, o qual é controlado na sociedade por vozes de autoridades que têm o poder de administrar a produção dos sentidos, e, portanto, a distribuição do conhecimento, contribuindo para estabelecer quais os sentidos que podem ser conhecidos e quais devem ser mantidos em silêncio.

O discurso de capa de Nova Escola (figura 2) revela que o ministro da Educação tem planos para melhorar a qualificação docente, no entanto, fica subentendida a 
compreensão de que aprimorar não significa, necessariamente, garantir solução para a problemática do ensino no Brasil. O discurso do governo representado na voz de Fernando Haddad funciona para por em circulação a vontade de verdade do governo, em um certo momento da história, pulverizando na sociedade o modo legítimo de ser professor, isto é, professores bem preparados é a característica que influencia na aprendizagem. $\mathrm{O}$ discurso de capa atravessado pelo discurso do governo movimenta o sentido de que é preciso ser qualificado para estar na ordem do ensino. Assim, Nova Escola configura a voz que representa uma ideologia influente, autorizada a eleger um sentido dominante, distribuí-lo e legitimá-lo perante a sociedade de consumo.

A identidade docente é constituída nas capas do impresso pelo processo de articulação entre técnicas de saber e mecanismos de poder, que identificam o professor afetado pelas relações de poder. Os resultados das análises mostram que o que caracteriza o professor desqualificado é a sua formação e o que define o profissional preparado é a sua ação demarcada pelos mecanismos pedagógicos que constituem o profissional do magistério. As duas capas analisadas nos mostram que entre a formação docente e a ação do quê e do como ensinar se estabelece a diferença entre o sucesso e o insucesso escolar, representado no modo de condução da prática pedagógica desenvolvida no processo de ensino. A técnica do saber representada pelas "fórmulas" da professora Zuleica e pelas "receitas" de países-modelo em Educação constituem a identidade docente, efeitos do poder enunciativo da revista Nova Escola. Para Foucault $(1979$, p. 12) "a verdade não existe fora do poder ou sem poder", por isso o discurso deve ser compreendido como uma construção que produz efeito de verdade e subjetiva o indivíduo moderno como produto do saber acometido pelas relações de poder. Produto este construído para ser consumido como a verdadeira realidade, quando "a única 'realidade' é a das aparências" (SILVA, 2002, p. 39). Identidade e verdade são criações deste mundo, uma espécie de movimento condicionado as relações de poder.

\section{REFERÊNCIAS}

\section{Fontes}

CIVITA, V. Carta do editor. Nova Escola, n. 1. 1986.

CIVITA, V. O que você precisa saber sobre a revista NOVA ESCOLA e a Fundação Victor Civita. Nova Escola, n. 216. 2008.

FIORE, Elizabeth de. Carta ao leitor. Nova escola, n. 116. 1998.

GROSSI, Gabriel. Carta do editor. Nova escola, n. 216. 2008.

NOVA ESCOLA. A revista do ensino fundamental, n. 116. 1998.

NOVA ESCOLA. A revista de quem educa, n. 216. 2008.

NOVA ESCOLA. Quem somos.2018. Disponível em: https://novaescola.org.br/quemsomos . Acesso em: 26 de mar. 2018. 


\section{Bibliografia}

CANDIOTTO, C. Foucault e a crítica da verdade. $2^{\mathrm{a}}$ ed. Belo Horizonte: Autêntica Editora, 2013.

COSTA, M. V. ; SILVEIRA, R. H. A revista Nova Escola e a constituição de identidades femininas. In: BRUSCHINI, C. e BUARQUE DE HOÇANDA, H. (orgs.). Horizontes plurais: novos estudos dos gêneros no Brasil. São Paulo: Fundação Carlos Chagas, 1998, P. 343-378.

FONSECA, M. A da. Michel Foucault e a constituição do sujeito. São Paulo: EDUC, 2003.

FOUCAULT, M. Histoire de la sexualité I:La volonté de savoir. Paris: Gallimard, 1976.

FOUCAULT, M. Microfísica do poder. Rio de Janeiro: Graal, 1979.

FOUCAULT, M. A ordem do discurso. 18ª ed. São Paulo: Edições Loyola, 2009.

FOUCAULT, M. A arqueologia do saber. $7^{\mathrm{a}}$ ed. Rio de Janeiro: Forense Universitária, 2010.

FUNDAÇÃO LEMANN. Nossa história. Disponível em: https://fundacaolemann.org.br/somos. Acesso em 26 de mar. 2018.

FUNDAÇÃO VICTOR CIVITA. Nossa História. 2018. Disponível em: https://fvc.org.br/especiais/nossa-historia/. Acesso em 26 de mar. 2018.

GREGOLIN, M. R. Análise do discurso e mídia: a (re)produção de identidades. Comunicação, mídia e consumo. 2007. v. 4 , n. $11, \quad$ p.11 - 25. DOI: http://dx.doi.org/10.18568/cmc.v4i11.105.

INDURSKY, F. A memória na cena do discurso. In: INDURSKY, F., MITTMANN, S., FERREIRA, M. C. L. (orgs.). Memória e história na/da análise do discurso. Campinas, SP: Mercado de Letras, 2011, p. 1-335.

LAGÔA, A. M. A representação da professora na revista Nova Escola. Dissertação de mestrado. Rio de Janeiro, 1998. Dissertação (Mestrado em Educação) - Faculdade de Educação, Universidade Federal do Rio de Janeiro.

NAVARRO, P. Uma definição da ordem discursiva midiática. In: MILANEZ. N.; GASPAR, N. R. (orgs.). A (des)ordem do discurso. São Paulo: Contexto, 2010, P. 7993.

ORLANDI, E. P. Análise de Discurso: princípios e procedimentos. $8^{\mathrm{a}}$ ed. Campinas SP: Pontes, 2009.

ORLANDI, E. P. As formas do silêncio: no movimento dos sentidos. $6^{\mathrm{a} e d .}$ Campinas SP: UNICAMPI, 2007. 
PÊCHEUX, M. O discurso: estrutura ou acontecimento. Campinas: SP: Pontes, 1990.

PEREIRA, M. H. F. Na nossa terra, em se plantando, elefante dá: Editora Abril (19502006) e livros vendidos em bancas de jornal. In: BRAGANLA, A., ABREU, M. (org.). Impresso no Brasil: dois séculos de livros brasileiros. São PAULO: Unesp, 2005, p. $303-316$.

REDAÇÃO. Nova Escola: Revista do Ensino Fundamental. Educabrasil. São Paulo: Midiamix, 2001. Disponível em: <http://www.educabrasil.com.br/nova-escola-revistado-ensino-fundamental/>. Acesso em: 24 de mar. 2018.

REVAH, D. (2013). Escola e Nova Escola: faces de um velho espelho. História da Educação. (Online). 2013. v. 17, n. 39. p. 79-99. Disponível em: http://dx.doi.org/10.1590/S2236-34592013000100006. Acesso em: 24 de mar. 2018.

RIPA, R. Nova escola - "a revista de quem educa": a fabricação de modelos ideais do ser professor. São Carlos - SP, 2010. 227 f. Tese de Doutorado. Universidade Federal de São Carlos. Disponível em: https://repositorio.ufscar.br/bitstream/handle/ufscar/2237/2903.pdf?sequence=1\&isAllo wed=y. Acesso em: 03 de mar. 2018.

ROMEU, S. S. de L.Os sujeitos de ensino na "página policial": uma análise das identificações dos sujeitos professor e aluno construídas no gênero notícia. Campina Grande, PB, 2012. 129f. Dissertação (Mestrado em Linguagem e Ensino) - Programa de Pós-Graduação em Linguagem e Ensino, Universidade Federal de Campina Grande. Disponível em: http://posle.ufcg.edu.br/index.php?title=2012. Acesso em: 18 de mai. 2018.

SILVA, Tomaz Tadeu da. Dr. Nietzsche, curriculista - com uma pequena ajuda do Professor Deleuze. In.: MOREIRA, Flávio Barbosa \& MACEDO, Elizabeth Fernandes de. (orgs.). Curríclo, práticas pedagógicas e identidades. Porto, Portugal: Porto Editora, 2002 .

Recebido em 10 de setembro 2018

Aceito em 20 de dezembro de 2018 